\title{
NEUROTIC PREDISPOSITION AND THE DISORGANIZATION OBSERVED IN EXPERIMENTS WITH THE CAMBRIDGE COCKPIT
}

\author{
BY \\ D. RUSSELL DAVIS \\ The Medical Research Council Unit of Applied Psychology, Cambridge \\ (RECEIVED 12TH JUNE, 1946)
}

THE changes in behaviour and feeling which were observed in experiments with the Cambridge Cockpit have been described in a previous paper (Davis, 1946). As had been expected, the effects seen in these experiments appeared essentially similar to those observed in aircrew subjected to the stress of operational flying. The first phase of the effects (namely, preoccupation, excessive activity of a restless and agitated kind, excitement, and irritability), resembled the acute anxiety reactions of aircrew. The second phase was characterized by inadequacy of activity, apathy, and discouragement. The first phase resembled the excitatory type, and the second the inhibitory type of reaction, as described in studies of experimental neurosis in laboratory animals, for example by Anderson and Parmenter (1941). The picture in the second phase was less uniform than that of the first, and the clinical counterpart less certain, particularly since diagnostic criteria vary considerably.' In some subjects there was a state resembling "hysteria", in others "fatigue syndrome", " depression", or " anxiety".

In the present paper certain observations will first be described to show why some of the test behaviour was regarded as essentially similar to the neurotic reactions of aircrew. The opportunity to prove this hypothesis was provided by the socalled "Harrogate" experiment, in which a large number of fit aircrew were examined both in the cockpit and also by one of two R.A.F. psychiatrists. If the disorganization observed in the tests was similar to that occurring in neurotic reactions to stress, it would be expected that the degree and type of disorganization would depend upon the grade and type of neurotic predisposition as assessed at interview. Furthermore, if those predisposed to neurosis tended to show a characteristic disorganization in the test, then pilots suffering from overt neurotic symptoms would also show corresponding test behaviour. It will be shown that this was in fact the case. In the previous paper it was suggested that the objective signs of the "overactivity" reaction resulted from persistence in trying to attain a high standard of performance and failure to do so.
On the other hand the "withdrawal" reaction represented a lowering of the standard to a level within the pilot's powers. These interpretations are confirmed by the findings to be described below. Thus the "overactivity" reaction was shown especially by those of obsessional disposition, whereas those of hysterical disposition tended to show the " withdrawal" reaction.

The experiments were also part of a plan to discover under what environmental conditions these kinds of disorganization occur. Such conditions may be contemporaneous or antecedent. It is rarely possible to predict variations of behaviour exactly from knowledge of contemporaneous variations of the environment, since the response of an organism to environmental variations is partially determined by past experience which has not been observed or in any way controlled. It is, therefore, necessary to introduce theoretical constructs such as " sets", " attitudes ", " behaviour tendencies", "neurotic predisposition", and the like, and to relate observed variations in behaviour to these intervening variables. Although it may not be known exactly how these variables are determined by antecedent variations of the environment, and although factors of inheritance may also be involved, there are practical advantages in relating the disorganization to an intervening variable such as neurotic predisposition, because neurotic predisposition may be independently assessed. Moreover, if it is also discovered what the relevant contemporaneous factors are, the concept of neurotic predisposition may be clarified, because with certain reservations, it may reasonably be argued that the antecedent factors are of the same general kind as the contemporaneous ones. The contemporaneous factors were investigated in later experiments than those described below, which deal only with the antecedent factors.

\section{Subjects}

Two main groups of subjects were tested. One group comprised 355 fit pilots of uniform flying experience. One hundred pilots who were patients attending a psychiatrist because of neurotic symptoms 
were also tested, but only 39 of these carried out a standardized test. The fit pilots and the patients were tested at a different place and time, although under similar conditions; and a small third group of 7 pilots served as an extra control group to the patients. These pilots were recovering from surgical conditions, but were normal from a psychiatric point of view.

\section{Assessment of Predisposition}

The fit pilots were interviewed by one of two R.A.F. psychiatrists. The details of the psychiatrists' methods need not be described here, and it suffices to say that an assessment of a pilot's grade of "predisposition to breakdown under the stress of operational flying" was made by a judicious weighing of the many details of the life-history and attitudes elicited at an interview of about forty-five minutes. The considerations discussed by Symonds (1943) governed the psychiatric interviews. Each subject was placed in one of four grades of predisposition: nil (favourable), slight, moderate, or severe. In addition, the presence or absence of any of ten special items of predisposition was reported, and suitable comments were appended. Only two such items require mention here, namely the " obsessional " item (by which was meant, however, little more than neat, methodical, and conscientious habit), and the item " morbid fears! anxiety".

The results .obtained from the two psychiatrists appeared to be sufficiently alike for the present purpose, and the data have been combined. Only four subjects were assessed as "severe", and they have been combined with those assessed as " moderate ". The patients were attending one of several psychiatrists, and for the present purpose the diagnosis accepted at the time of the test has been regarded as the correct one.

\section{Test Classification}

The subjects were classified on the basis of their test scores according to the predominant features of the disorganization. of activity. The method was described in the previous paper. Those whose performance was relatively well maintained at the end of a forty-six-minute test were placed in the " normal " class. Those whose activity was high - as measured by their "movements" scores-relative to the length of time for which errors were allowed to persist-as measured by scores of "total duration of errors"-were placed in the "overactivity" class. Those whose errors were persistent, relative to their activity, were placed in the "withdrawal" class. Subsidiary modes of classification were also adopted and will be referred to below as occasion requires. Of the patients, only the 39 who carried out the standardized test were classified.

\section{Results}

Preliminary Observations.-The effects observed in the cockpit test itself were often part of a more general reaction comprising frankly neurotic features, as the following case illustrates. This subject's history showed that he was highly predisposed to neurosis. His test reaction was typical of the " overactivity " class, and it was clear that it reflected an acute anxiety state.

This pilot had recently recovered from an anxiety state, by reason of which he had been suspended from flying on the report of his crew after fourteen operations in a heavy bomber. He had never enjoyed flying and developed symptoms after a few sorties, but his symptoms did not make him obviously ill until his home was bombed and he had quarrelled with his fiancée, who wanted him to give up flying. He was said to be of a retiring, unaggressive, and conscientious disposition.

His performance deteriorated rapidly on the first test; the number of corrections showed a very big increase, and the control movements became restless, large, and forceful. At the end of the test he was flushed and sweating profusely; he was excited and commented with some show of emotion: " the harder I tried the worse it got . . . I wanted to smash it up, as it was the only way out, and I pulled the stick backwards and forwards with the intention of doing so". During the night after the test he had a vivid dream, of which he said: "I woke up feeling distressed and angry ... I I felt I had let myself down badly. I dreamt of pieces flying off the cockpit . . . I thought I had wrecked it, and it was my fault".

He was depressed and anxious all the next day; and on the day after, when he came for a second test, he appeared more worried and tense than before. This 0 time the deterioration was more rapid, and the test had $\bar{Q}$ to be stopped, as his control movements were of such $\mathrm{a} \stackrel{\mathrm{C}}{\mathrm{C}}$ size and force that the mechanism was endangered. His sleep was again disturbed by a dream similar to the first, and he asked to do a third test on the following day in order to retrieve his previous failure. On this occasion it was arranged, without his knowledge, that the machine was much easier to control, and he achieved a moderate degree of accuracy. He appeared satisfied, and, on being questioned a few days later, he reported that he had given no further thought to the test.

Sometimes the effects observed in the test were a recapitulation of a previous neurotic illness, as the following case illustrates.

This pilot, whose keenness and determination had earned him the D.F.C., had been suspended from flying after twenty-one bombing operations, several of which had been unusually hazardous. After five particularly hazardous sorties in seven days, certain eye symptoms, of which he had been aware previously, became worse; he grew tired, and his confidence diminished rapidly. On his last sortie, which was relatively easy, an untoward incident occurred on the way home: one engine failing suddenly. He handled the situation adequately, but then became dazed. He said afterwards that he had been unable to see the instruments properly, as they had danced in front of his eyes and seemed blurred. He was relieved by his navigator, who reported that the pilot was in a curious, dreamy state.

At the time of the test he was free from symptoms and was at duty in a ground job. However, he showed abnormal energy and restlessness, being unable, for instance, to read a book for more than twenty minutes at a time without having to turn to a more active occupation. A number of items in his previous history made it somewhat surprising that, with his constitutional nervousness, he had made as big an operational contribution to the war effort as in fact he had, but it is probable that an obsessional conscientiousness had kept him going. 

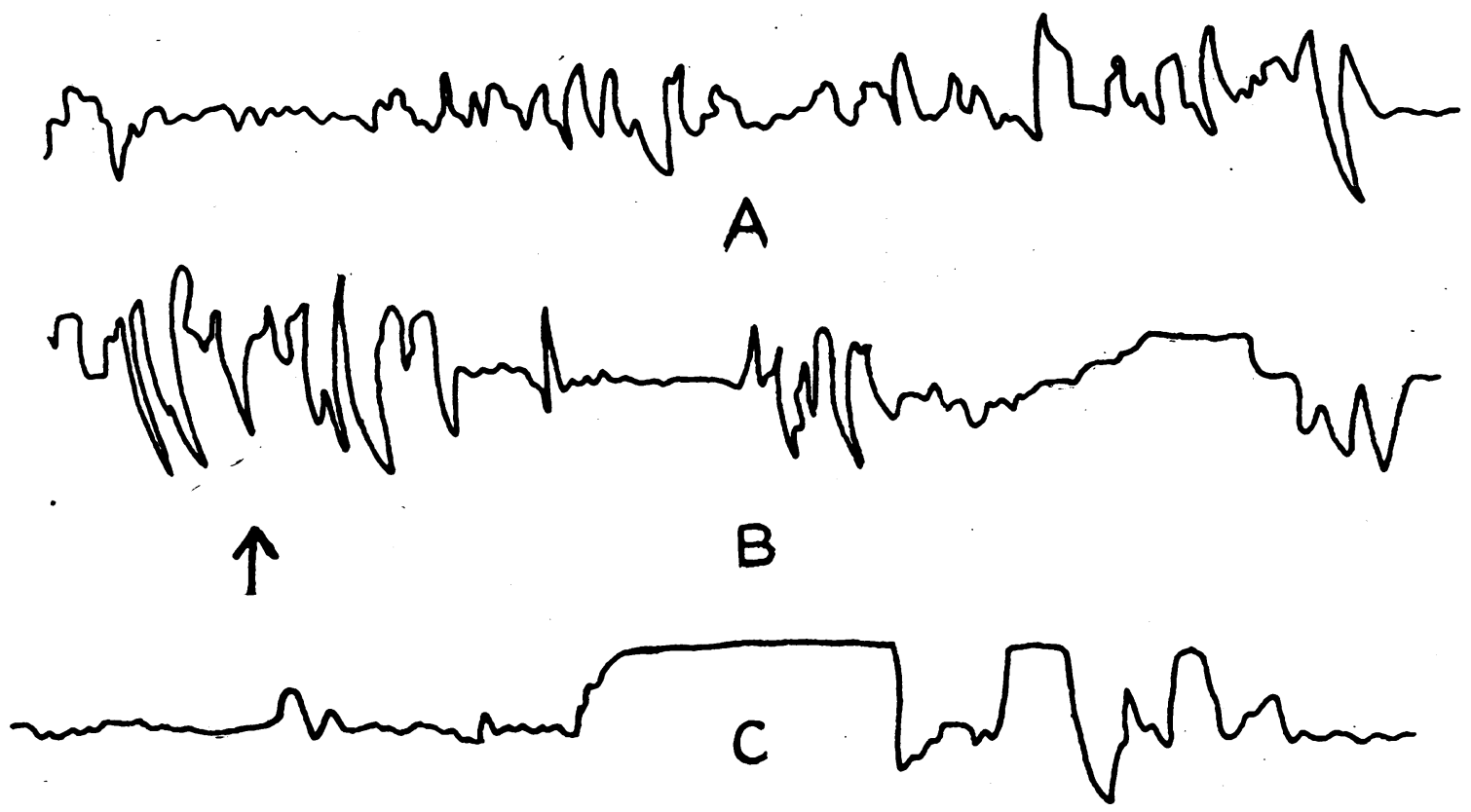

5 mins.

Extracts of a side-slip record.-A illustrates the performance in the first ten minutes of the test; B and C, which are not continuous, show the performance after seventy and eighty minutes respectively. Shortly after the subject forgot to reset the fuel indicator, at the point indicated by the arrow, his performance showed a marked change. The large, rapid fluctuations, which were characteristic of the performance previously, occur only occasionally, and in $\mathrm{C}$ a large deviation persists for more than two minutes.

There was no doubt about his keenness to do the test well, and he set himself very high standards of accuracy, which from the start he had difficulty in attaining. His control movements increased steadily in size and force and were considerably disturbed by inappropriate movements. The movement and correction scores were high, but the average duration of errors was relatively small. The illustration shows extracts from the record of the side-slip instrument. At the point indicated by the arrow, he forgot to reset the fuel indicator, and the engine failed. He made the correct response, but within a few minutes his behaviour underwent a dramatic change. He no longer carried out the prescribed movements, and his activity fell away to a very low level, large deviations of the instruments being allowed to persist for as long as two minutes. The only evidence of his previous pattern of activity was an occasional burst of restless movement. At the end of the test he appeared haggard and pale and said in explanation: "I nearly went to sleep ... I forgot what I was doing ... I I seemed to be powerless to do anything except fly straight and level and not forget the petrol again. ... The instruments were blurred".

This incident in the test situation was regarded as being similar to that which occurred on his last operational flight.

Eye symptoms of a neurotic kind were relatively frequent developments in the test, being reported by 6 of the group of fit pilots. Tests of fit pilots had to be interrupted twice because of giddiness and because subjects thought that they might vomit. Bilateral ankle clonus persisted for about twenty minutes in another fit pilot. Among the patients exacerbation of existing hysterical symptoms and the appearance of new symptoms were both common.

Test Class and Predisposition.-The following Tables show that experimental subjects, whether fit pilots or patients, were distributed among the various test classes in a way consistent with the hypotheses set out at the beginning of the article. Conventional statistical methods were applied, and by "significant " is "meant that a similar result would occur by chance less often than once in twenty times.

There was a significant association of grade of predisposition and test class, whether normal or abnormal (Table I). It may also be demonstrated

TABLE I

\begin{tabular}{|c|c|c|c|c|c|}
\hline \multirow{2}{*}{$\begin{array}{c}\text { Grade of } \\
\text { predisposition }\end{array}$} & \multicolumn{3}{|c|}{ Test class } & \multirow{2}{*}{ Total } & \multirow{2}{*}{$\stackrel{\%}{\%}$} \\
\hline & Normal & $\begin{array}{l}\text { Over- } \\
\text { activity }\end{array}$ & $\begin{array}{l}\text { With- } \\
\text { drawal }\end{array}$ & & \\
\hline $\begin{array}{l}\text { Nil } \\
\text { Slight } \\
\text { Moderate }\end{array}$ & $\begin{array}{r}130 \\
113 \\
25\end{array}$ & $\begin{array}{l}13 \\
32 \\
14\end{array}$ & $\begin{array}{r}12 \\
9 \\
7\end{array}$ & $\begin{array}{r}155 \\
154 \\
46\end{array}$ & $\begin{array}{l}84 \\
73 \\
54\end{array}$ \\
\hline Total & 268 & 59 & 28 & 355 & 75 \\
\hline$\%$ Moderate & 9 & 24 & 25 & 13 & \\
\hline
\end{tabular}

Predisposition grade and test class-fit pilots.

from the data in this table that in the case of the " overactivity" class the association extended over the whole range of assessments. In the case of the "withdrawal" class, however, the proportion of 
"nil" assesșments was similar to that of the " normal" class, although there was also a preponderance of " moderate" assessments.

Pilots suffering from neurotic symptoms fell significantly less often into the " normal" test class than did the fit pilots (Table II).

TABLE II

\begin{tabular}{l|c|c|c|c|c|c}
\hline & \multicolumn{3}{|c|}{ Test class } & & & \\
$\begin{array}{c}\text { Experi- } \\
\text { mental } \\
\text { group }\end{array}$ & Normal & $\begin{array}{c}\text { Over- } \\
\text { activity }\end{array}$ & $\begin{array}{c}\text { With- } \\
\text { drawal }\end{array}$ & Total & $\%$ Normal & $\begin{array}{c}\text { Ratio of } \\
\text { Overactivity } \\
\text { to With- } \\
\text { drawal }\end{array}$ \\
\hline $\begin{array}{l}\text { Fit } \\
\text { Patients }\end{array}$ & 268 & 59 & 28 & 355 & 75 & $2.1: 1$ \\
$\begin{array}{c}\text { Patient } \\
\text { control }\end{array}$ & 73 & 11 & 15 & 39 & 33 & $0.7: 1$ \\
\hline
\end{tabular}

Neurosis and test class-patients and fit pilots.

Those fit pilots rated as "obsessional" who fell into the abnormal test classes showed a significant tendency to fall into the "overactivity" rather than the "withdrawal" class. This tendency was particularly marked in the case of subjects who were also assessed as slight or moderate. When the "obsessional" item was combined with the item " anxiety: morbid fears", a particularly high proportion fell into the abnormal test classes. These findings are shown in Table III.

TABLE III

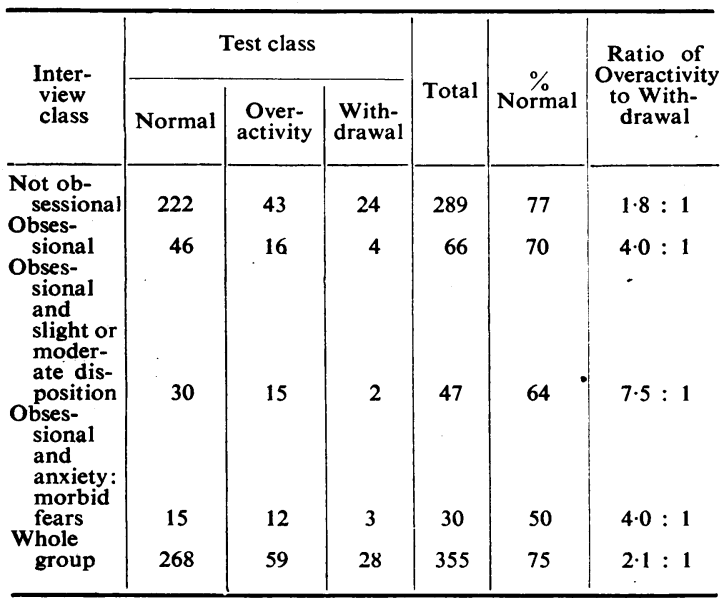

The obsessional and the overactivity class-fit pilots.

If the obsessional trait was a single positive finding, and the predisposition was assessed as nil (" nil, obsessional" class), the test behaviour was favourable, in that no subject was graded in the abnormal test classes. The test behaviour was unfavourable, however, inasmuch as very few such subjects did especially well in the test. Thus the " normal" class was subdivided into "plus", " average", and " minus" on the basis of the main and subsidiary scores; only a small proportion of the " nil, obsessional" were in the "plus" class in comparison with those with no item present (" nil -" class). The proportion in the "plus" class of those with a single item'other than "obsessional" present (" nil, one item" class) was intermediate. These findings are shown in Table IV.

TABLE IV

\begin{tabular}{l|r|r|r|r|r|r|r}
\hline & \multicolumn{5}{|c|}{ Test class } & Total & $\begin{array}{r}\% \\
\text { Interview } \\
\text { class }\end{array}$ \\
\cline { 2 - 6 } & Plus & $\begin{array}{r}\text { Normal } \\
\text { average }\end{array}$ & Minus & $\begin{array}{r}\text { Over- } \\
\text { activity }\end{array}$ & $\begin{array}{r}\text { With- } \\
\text { drawal }\end{array}$ & & \\
\hline $\begin{array}{c}\text { Nil, obses- } \\
\text { sional }\end{array}$ & 1 & 10 & 1 & 0 & 0 & 12 & 8 \\
$\begin{array}{c}\text { Nil - } \\
\text { Nil, one } \\
\text { item }\end{array}$ & 30 & 57 & 8 & 11 & 12 & 118 & 25 \\
$\begin{array}{c}\text { Whole } \\
\text { group }\end{array}$ & 64 & 172 & 32 & 59 & 28 & 355 & 18 \\
\hline
\end{tabular}

The " obsessional " displayed other test features of interest. Thus their performance was significantly more often rated as " erratic" than that of those not classed as " obsessional" (Table V). The rating of "erratic" was presumed to indicate irregular distribution of attention over the various aspects of

TABLE V

\begin{tabular}{|c|c|c|c|c|}
\hline \multirow{2}{*}{ Interview class } & \multicolumn{2}{|c|}{ Test class } & \multirow{2}{*}{ Total } & \multirow{2}{*}{$\%$ Erratic } \\
\hline & Erratic & Not erratic & & \\
\hline $\begin{array}{lll}\text { Obsessional ... } & \ldots & \ldots \\
\text { Not obsessional } & \ldots & .\end{array}$ & $\begin{array}{l}13 \\
17\end{array}$ & $\begin{array}{r}53 \\
272\end{array}$ & $\begin{array}{r}66 \\
289\end{array}$ & $\begin{array}{r}20 \\
6\end{array}$ \\
\hline Total $\ldots$. & 30 & 325 & 355 & 8 \\
\hline
\end{tabular}

Erratic test behaviour and the obsessional trait-fit pilots.

the task and was made from observations of intermittency of errors in respect of a particular instru-? ment, or of irregularity in the movements of a particular control. There were no reasons to suppose that this association was due to features other than the obsessional trait, and there was no association between the "erratic" rating and the degree of predisposition.

The same tendency to irregular distribution of attention was suggested by the fact that, of the 10 subjects who showed a marked failure to carry out the test instructions in respect of the timing and sequence of the manœuvres, 4 were classed as "obsessional". There was no evidence that this failure to carry out the test instructions was due to faulty comprehension or defect of intelligence (intelligence test scores being available for all subjects). Rather did it seem due to preoccupation with other aspects of the task which were given greater importance by the subject.

Among the fit pilots no psychiatric assessment of any special tendency to hysterical reactions was made as a routine. Judging by the comments appended to the interview assessments, however, there were inconclusive indications that those in the "withdrawal" class were more predisposed in this respect than those in the "overactivity" class. Examination of the test results of the patients showed that those diagnosed as " hysteria" tended to show the "withdrawal" reaction. Thus 6 out 
of 8 such patients were in the "withdrawal" class. Moreover, the majority of the patients in the abnormal classes fell into the "withdrawal " class, in contrast to the findings in the group of fit pilots (Table II), as might be expected if the "withdrawal" reaction represented a later stage of development than the "overactivity" reaction, as was shown in the previous paper (Davis, 1946).

Patients in the "withdrawal" class had a significantly less satisfactory history in respect of operational flying than those in the "overactivity" class. Only 4 of the "withdrawal" class had made operational flights, the other 11 having developed symptoms before reaching an operational squadron. In contrast, 10 of the 11 patients in the "overactivity" class, and 7 out of the 13 patients in the "normal" class, had carried out flying operations before breaking down.

A further point of interest is shown in Table IV. Compared with the "nil, obsessional" and " nil, one item" subjects ( 0 per cent.), a relatively high proportion of the " nil, _ " subjects (19 per cent.) fell into the abnormal classes. There was not sufficient evidence on which to interpret this finding, but it may be noted that a slightly larger number of the "nil —" subjects were in the "withdrawal" class than in the "overactivity" class, this being the reverse of the normal ratio in fit subjects. Furthermore, the discrepancy was more marked in officers than in sergeant pilots. Two hypotheses would fit these findings. Firstly, the possession of one-defect, or one item of predisposition, if it was not sufficient to amount to a degree of predisposition, had a favourable effect in determining success in the test-for example, by securing good motivation. Secondly, some of the " nil - " subjects were poor material, but the psychiatrist failed to obtain a true and detailed account of their history; this failure was more likely to occur in the case of individuals who tended to evasion (withdrawal) rather than in those who tended toward anxiety under stress. Evidence obtained in the "follow-up" of these pilots seemed to support the latter hypothesis.

\section{Discussion}

These results justify the conclusion that the degree and type of the disorganization observed in the test depended upon the grade and type of the neurotic predisposition. This conclusion supports, although it does not compel, the hypothesis that the disorganization of activity observed in the test was of the same kind as that occurring in the neurotic reactions of aircrew to stress. Similarly, the results confirm the suggestions made in the previous paper that the "overactivity" reaction represented persistence against the difficulties of the test, and that the second reaction was appropriately named "withdrawal ".

As has been said, the effects observed in the cockpit tests resembled the disorders shown by aircrew. Especially good examples of this resemblance were found in a group of pilots who had received from a R.A.F. psychiatrist the diagnosis of "fatigue syndrome". This group was a highly-selected one, composed of 12 pilots who, during a second operational tour, were dissatisfied with their health although they did not show definite neurotic symptoms. At an interview with the author the majority said that some "stickiness" of attention became a source of difficulty when landing or flying on instruments. By this they meant that they tended to be preoccupied by a single aspect of their task. Restlessness, impatience, and irritability were also characteristic complaints, which had a counterpart in the "overactivity" reaction. High standards of efficiency were often held to in spite of disabilities which made them more difficult to attain, and several of the group had "obsessional" habits. The tendencies of which they complained were subsequently observed in tests in the cockpit.

The strong supposition that the disorganization of activity observed in the cockpit tests was essentially a neurotic disturbance, closely related to the acute neurotic reactions of aircrew, has a consequence of some importance. A fair amount of research, mainly with laboratory animals, has been carried out in recent years on the so-called experimental neuroses. The results of this research have not generally been regarded by psychiatrists as of great significance, because it was doubtful whether the experimental disorders were the same as those encountered in human neurosis. A similar objection in the case of the effects observed in the cockpit has been met by the arguments developed in this paper. It appears reasonable to maintain that neurosis has been produced experimentally in human subjects in a form in which it can readily be studied by further experiment. It thus becomes possible to apply and test the hypotheses developed in research in the experimental neuroses in much closer relation to human disorders.

Although it has often been shown (e.g. Hunt, 1944) that subjects of neurotic disposition do badly on many kinds of psychological test, results as clear-cut and detailed as those presented above have not been reported. Moreover, the main results were obtained from subjects who, although predisposed, were without symptoms and who, being pilots, were highly selected in respect of many favourable qualities. In the " obsessional " group the findings were particularly definite, although their test performance could not be described simply as good or bad. In the experiments of Culpin and Smith (1930), however, the "obsessional" were distinguished by their superior performance on the dotting test, but a performance of a different kind was measured and the "obsessional" trait was defined differently. It should be noted that, in the "Harrogate" experiment, the rating " obsessional" indicated only a slight deviation from normality.

These results also suggest that the Cambridge Cockpit test might be employed successfully to predict the reaction of individuals to flying stress, and an object of the "Harrogate" experiment was to assess its usefulness in this respect. Unfortunately, insufficient "follow-up" data were obtained 
to reach a definite conclusion, although those which were obtained were most encouraging. Nevertheless the test has serious disadvantages as a selection method, since it is lengthy and can be applied only to those who have had some experience of flying. The apparatus is elaborate and requires expert maintenance. It is hoped, however, that the essential features of the cockpit test may be incorporated in new tests of a more suitable kind.

\section{Summary}

It is contended that the disorganization of activity observed in the Cockpit test is essentially similar to that occurring in the neurotic reactions of aircrew to stress. In tests, the " overactivity" reaction resembled the acute anxiety reactions of aircrew, and the "withdrawal" reaction" resembled various neurotic reactions, of which some have been labelled " hysteria". It has been shown that in some cases the effects observed in the test were part of a more general reaction comprising frankly neurotic features. In some cases the test reaction recapitulated a previous neurotic illness. It has also been shown that the degree and type of the disorganization observed in the test depended upon the grade and type of the neurotic predisposition as assessed at an independent psychiatric interview. The test behaviour of experimental subjects, whether fit pilots or pilots suffering from overt neurotic symptoms, tended to be of the kind expected. Thus the test behaviour was abnormal in two-thirds of the patients, but only in one-quarter of the fit pilots. The " overactivity" reaction was shown especially by those assessed as obsessional at interview, whereas the " withdrawal" reaction tended to be shown by those of hysterical disposition.

\section{Acknowledgements}

The "Harrogate" experiment was carried out on behalf of the Flying Personnel Research Committee of the R.A.F., and use was made of the interview data collected by Drs. J. Flind and B. Cates, then specialists in neuropsychiatry in the R.A.F. The experiments in which patients were tested were instigated by the late Dr. R. D. Gillespie, then consultant in neuropsychiatry. I am indebted to Air Marshal Sir Harold Whittingham, K.B.E., Director General of the Medical Services of the R.A.F., for encouragement in carrying out the research and for permission to publish these results. My thanks are due to the many members of the R.A.F. and the W.A.A.F. who gave assistance.

\section{REFERENCES}

Anderson, O. D., and Parmenter, R. (1941). Psychosomat. Med., Monograph, 2, Nos. 3 and 4.

Culpin, M., and Smith, M. (1930). "The Nervous Temperament." Industr. Hlth. Res. Bd. Rep. No. 61 . London, H.M.S.O.

Davis, D. R. (1946). Journal of Neurology, Neurosurgeryo and Psychiatry, 9, 23.

Hunt, J. McV. (1944). " "Psychological Deficit" in " Perه sonality and the Behaviour Disorder," Vol. II Chap. 32. New York. Ronald Press Co.

Symonds, C. P. (1943). Brit. med. J., 2, 703; 740. 